\title{
Epidemiology of \\ community-acquired pneumonia
}

\author{
Thomas J Marrie MD FRCPC
}

\begin{abstract}
TJ Marrie. Epidemiology of community-acquired pneumonia. Can J Infect Dis 1998;9(Suppl E):27E-29E.
Community-acquired pneumonia (CAP) is a common and a serious illness. Streptococcus pneumoniae accounts for about half of all cases of CAP. Atypical pneumonia, ie, pneumonia due to Mycoplasma pneumoniae, Chlamydia pneumoniae, Legionella species or viruses, is more common among patients treated on an ambulatory basis where these pathogens can collectively cause up to half of all cases of pneumonia. Changes in patient and microbe populations alter the epidemiology of pneumonia. Aspiration and Gram-negative rod pneumonia tend to be more common in nursing home populations. The emergence of macrolide- and beta-lactam-resistant $S$ pneumoniae has major implications for the approach to patients with CAP.
\end{abstract}

Key Words: Community-acquired pneumonia, Epidemiology

\section{Épidémiologie de la pneumonie extra-hospitalière}

La pneumonie extra-hospitalière (PEH) est une maladie fréquente et grave, due à Streptococcus pneumoniae pour presque la moitié de l'ensemble des cas. Les pneumonies atypiques, pneumonies causées par Mycoplasma pneumoniae, Chlamydia pneumoniae, des espèces de Legionella ou des virus se rencontrent plus fréquemment chez les patients traités sur une base externe. En effet, ces pathogènes peuvent collectivement causer près de la moitié de tous les cas de pneumonie. Les modifications dans les populations de patients et de bactéries modifient l'épidémiologie de la pneumonie. Les pneumonies à bacilles gram-négatifs et celles dues à des aspirations semblent être plus fréquentes dans les populations des centres d'accueil. L'émergence de la résistance de $S$. pneumoniae aux macrolides et aux bêta-lactamines a des implications substantielles pour ce qui est de l'approche du traitement des patients atteints d'une PEH.

$\mathrm{T}$ here are three to four million cases of communityacquired pneumonia (CAP) per year in the United States, with about 3.5 million patients receiving treatment on an ambulatory basis (1). Pneumonia is the fifth leading cause of death, and the costs associated with the diagnosis and management of pneumonia are estimated to be several billion US dollars per year.

Pneumonia used to be a simple entity diagnostically but was a very difficult problem therapeutically. In 1938, Streptococcus pneumoniae accounted for almost all cases of CAP. Unfortunately, there was no specific therapy. In the present decade, the situation is reversed. Specific therapy is available for almost every microbial cause of pneumonia, but it is to difficult to make an etiological diagnosis. Many causes of CAP have been identified, but in $30 \%$ to $40 \%$ of cases the etiology remains unknown $(2,3)$. To further complicate matters, the population at risk for CAP has changed. The portion of the population 65 years of age or older is the fastest growing population (4). Among other things, this has led to a new nosological entity - nursing home-acquired pneumonia. The explosion of infection due to human immunodeficiency virus (HIV) (5) and the success of organ transplantation, with its attendant need for ongoing immunosuppression, has led to an increasingly larger number of immunocompromised individuals in the general population. Health care economics (ie, the pressure on the health care system to do more with less) has led to treating more patients at home than in the past. In a recent study (January 1995 to August 1995) in which all pa-

Departments of Medicine and Microbiology, Dalhousie University and the Queen Elizabeth II Health Sciences Centre, Halifax, Nova Scotia Correspondence: Dr Thomas I Marrie, Queen Elizabeth II Health Sciences Centre, 1278 Tower Road, Room 5014 ACC, Halifax,

Nova Scotia B3H 2Y9. Telephone 902-473-5553, fax 902-473-7394, e-mail tmarrie@is.dal.ca 
TABLE 1

Rank order of etiological agents in patients with communityacquired pneumonia
1. Streptococcus pneumoniae
2. Mycoplasma pneumoniae
3. Chlamydia pneumoniae
4. Haemophilus influenzae
5. Aerobic Gram-negative bacilli*
6. Staphylococcus aureus
7. Legionella species
8. Pneumocystis carinii
9. Mycobacterium tuberculosis
10. Moraxella catarrhalis

*Escherichia coli, Klebsiella species, Serratia species, Proteus species, Providenca species, Enterobacter species and Pseudomonas aeruoginosa. Data adapted from reference 30

tients with CAP admitted to Victoria General Hospital for discharge on day 3 were assessed, the author found that only $10 \%(14 / 140)$ fit the definition of medical stability for discharge (unpublished data). Despite the fact that most patients with CAP are treated as out-patients, CAP patients have not been studied frequently. Macfarlane (6) found only 12 studies that considered out-patients with pneumonia in any manner, and most of these studies had deficits in design.

\section{EPIDEMIOLOGY OF CAP}

Incidence: The attack rates for CAP are highest in patients at extreme ages (6-10). Foy et al (7) found that the overall attack rate of pneumonia was $12 / 1000$ persons in a study of 180,000 individuals in the 1960 s and 1970s. For those aged four years or younger, it was $12 / 1000$ to $18 / 1000$ persons, while it was $1 / 1000$ to $5 / 1000$ persons for the age group five to 60 years. Macfarlane (6) found that the yearly incidence of pneumonia in adults was one to three cases per 1000 adults in a study carried out in England. Studies focusing on pneumonia due to specific microbial agents suggest that the rate for pneumococcal pneumonia is 37.5 cases per 100,000 individuals per year (8). The hospitalization rate for pneumonia ranges from $17 \%$ (11) to $35 \%$ (unpublished data) for those patients seen in their physicians' offices and 50\% for those seen in an emergency room (12).

Etiology: Patients with CAP requiring admission to hospital have been studied extensively $(2,3,8,12-27)$. The results of two recent studies were remarkably similar $(2,3)$. One-third to almost one-half of the cases were of unknown etiology. From its dominant position six decades ago, $S$ pneumoniae now causes a mere $8 \%$ to $10 \%$ of CAP requiring hospitalization. While a large number of the pneumonia cases of unknown etiology can be attributed to inadequate diagnostic studies (eg, respiratory secretions not available for culture), it is likely that there are still agents that are causing pneumonia that have not been discovered or that new agents will emerge as changes occur in the population at risk. This thesis is substantiated by the findings of Ortqvist et al (28), who were unable to make an etiological diagnosis in five of 24 (21\%) patients with CAP despite bronchoscopy and serological studies in all patients. However, using antibodies to $S$ pneumoniae pneumolysin and pneumolysin immune complexes as a diagnostic tool for pneumococcal pneumonia, Kauppinen et al (29) found that $S$ pneumoniae accounted for $55 \%$ of pneumonia cases. Table 1 summarizes the most common causes of CAP requiring admission to hospital. These data are from studies that examined 5225 cases of CAP (30).

There have been very few studies of the etiology of pneumonia in out-patients (31). In a study of 75 such patients, an etiological diagnosis by serological methods was made in $45 \%$ of cases (32). Mycoplasma pneumoniae accounted for $65 \%$ of the cases of known etiology and $29 \%$ of the cases overall. Chlamydia pneumoniae caused 5\%, and Legionella pneumophila $3 \%$ of the cases overall. Other agents identified included infiuenza A (7\%), Coxiella burnetii $(3 \%)$ and adenovirus (3\%). Thirty-five per cent of the 75 patients were hospitalized. The mortality rate was $4 \%$. Similar results were obtained in a practitioner-based study in Switzerland (33). Fourteen of 161 $(8.7 \%)$ patients required hospitalization. The overall morality rate was $1.2 \%$. No etiological diagnosis was made in $47 \%$ of cases. Agents implicated included the following: $S$ pneumoniae (17 cases), Haemophilus species (two cases), $M$ catarrhalis (one case), Streptococcus species (one case), Legionella species (three cases), Chlamydia species (nine cases), M pneumoniae (28 cases), C burnetii (three cases), influenza (19 cases) and other respiratory viruses (seven cases). Marrie TJ et al studied 149 ambulatory patients with CAP using serological methods (34). The authors were able to define an etiological agent in $41.7 \%$ of patients. $M$ pneumoniae accounted for $22.8 \%$ of the cases (Table 2 ).

Comorbidity: Most patients who are hospitalized with pneumonia have one or more comorbidities. Such comorbidities are often age dependent. The mean number of comorbidities increased from 0.73 for those 30 years of age or younger to 2.75 for those in the age group 71 to 80 years (35). Alcoholism, chronic obstructive pulmonary disease, ischemic heart disease, malignancy, diabetes mellitus and neurological disease are all important in either predisposing to pneumonia (neurological disease resulting in aspiration) or influencing recovery from pneumonia (chronic obstructive pulmonary disease, ischemic heart disease, malignancy). In contrast, $59 \%$ of patients with CAP treated on an ambulatory basis had no comorbidity.

Outcome: Pneumonia is a serious illness. The overall mortality rate is $1 \%$ to $3 \%$. For patients requiring hospitalization, the mortality varies from $6 \%$ to $24 \%$ depending on the selection criteria $(2,3,12-31,36)$.

Host factors: There are many immunocompromised persons living in the community including patients with HIV infection and those receiving immunosuppressive medications to prevent transplanted organ rejection or to suppress an aberant immune response. These individuals may develop pneumonia due to any one of the 100 different microbes that cause pneumonia in the immunocompetent host. In addition, Pneumocystis carinii and various fungi are also pathogens in this population. Despite prophylaxis for its prevention, $P$ carinii is still an important 
pathogen in patients with HIV infection. Furthermore, underlying disease (such as lymphoma recurrence) or pulmonary chemotherapeutic agents can also mimic pneumonia in some immunocompromised patients. Thus, an aggressive approach to diagnosis and therapy is necessary.

Organism factors: Penicillin-resistant $S$ pneumoniae is now a world-wide problem. The risk factors for penicillin-resistant $S$ pneumoniae infection are previous use of beta-lactam antibotics, alcoholism and noninvasive disease (36). ClavoSanchez et al (36) defined invasive disease to mean isolation of $S$ pneumoniae from a normally sterile site, eg, blood, pleural fluid; all other infections were termed noninvasive. In addition to the foregoing factors, age younger than five or older than 65 years is predictive of multidrug-resistant $S$ pneumoniae (36).

\section{REFERENCES}

1. Ashby BL. Treatment of pneumonia; new strategies for changing pathogens. Clin Ther 1991;13:637-50.

2. Fang GD, Fine M, Orloff J, et al. New and emerging etiologies for community-acquired pneumonia with implications for therapy. A prospective multicenter study of 359 cases. Medicine (Baltimore) 1990;69:307-16.

3. Marrie TJ, Durant H, Yates L. Community-acquired pneumonia requiring hospitalization: 5-year prospective study. Rev Infect Dis 1989;11:586-99.

4. Fredman L, Haynes SG. An epidemiologic profile of the elderly. In: Phillips HT, Gaylord SA, eds. Aging and Public Health. New York: Springer, 1985.

5. Update: acquired immunodeficiency syndrome - United States, 1981-1990. MMWR 1991;40:358-63, 369.

6. Macfarlane J. Community-acquired pneumonia. Br J Dis Chest 1987;81:116-27.

7. Foy HM, Cooney MK, Allan I, Kenny GE. Rates of pneumonia during influenza epidemics in Seattle, 1964 to 1975 . JAMA 1979;241:253-8.

8. Mufson MA, Oley G, Hughey D. Pneumococcal disease in a medium-sized community in the United States. JAMA $1982 ; 248: 1486-9$.

9. Davidson M, Schraer CD, Parkinson AJ, et al. Invasive pneumococcal disease in an Alaska native population, 1980 through 1986. JAMA 1989;261:715-8.

10. Foy HM, Cooney MK, McMahan R, Grayston JT. Viral and mycoplasmal pneumonia in a prepaid medical care group during an eight-year period. Am J Epidemiol 1973;97:93-102.

11. Foy HM, Wentworth B, Kenny GE, Kloeck JM, Grayston JT. Pneumococcal isolations from patients with pneumonia and control subjects in a prepaid medical care group. Am Rev Respir Dis 1975; 111:595-603.

12. Fekety FR Jr, Caldwell J, Gump D, et al. Bacteria, viruses, and mycoplasmas in acute pneumonia in adults. Am Rev Respir Dis 1971;104:499-507.

13. Sullivan RJ Jr, Dowdle WR, Marine WM, Hierholzer JC. Adult pneumonia in a general hospital. Etiology and host risk factors. Arch Intern Med 1972;129:935-42.

14. Dorff GJ, Rytel MW, Farmer SG, Scanlon G. Etiologies and characteristic features of pneumonia in a municipal hospital. Am I Med Sci 1973;266:349-58.

15. Garb JL, Brown RB, Garb JR, Tuthill RW. Differences in etiology of pneumonias in nursing home and community patients. JAMA 1978;240:2169-72.

16. MCNabb WR, Shanson DC, Williams TDM, Lant AF. Adult community-acquired pneumonia in central London. J Roy Soc Med 1984;77:550-5.

17. Macfarlane JT, Finch RG, Ward MJ, Macrae AD. Hospital study of adult community-acquired pneumonia. Lancet 1982;2:255-8.

18. Kerttula Y, Leinonen M, Koskela M, Makela PH. The aetiology of pneumonia. Application of bacterial serology and basic laboratory methods. J Infect 1987;14:21-31.

19. Holmberg H, Badin L, Jonsson I, Krook A. Rapid aetiological diagnosis of pneumonia based on routine laboratory features. Scan J Infect Dis 1990;22:537-45.

20. Bath JCIL, Boissard GPB, Calder MA, Moffat MAJ. Pneumonia in hospital practice in Edinburgh 1960-1962. Br J Dis Chest 1964;58:1-16.

21. Larsen RA, Jacobson JA. Diagnosis of community-acquired
TABLE 2

Etiology of community-acquired pneumonia in 149 ambulatory patients

\begin{tabular}{lc}
\hline Agent & $\begin{array}{c}\text { Number (\%) of cases due to } \\
\text { agent }\end{array}$ \\
\hline Undetermined & $72(48.3)$ \\
Mycoplasma pneumoniae & $34(22.8)$ \\
Chlamydia pneumoniae & $16(10.7)$ \\
M pneumoniae and C pneumoniae & $5(3.4)$ \\
Influenza A & $4(2.7)$ \\
Coxiella burnetti & $4(2.7)$ \\
Adenovirus & $3(2.0)$ \\
Influenza B & $3(2.0)$ \\
Other* & $3(2.0)$ \\
Chlamydia psittaci & $2(1.3)$ \\
Adenovirus and influenza A & $1(0.7)$ \\
Influenza A and C pneumoniae & $1(0.7)$ \\
Legionella species & $1(0.7)$
\end{tabular}

* Included are three patients with bacterial pneumonia caused by Streptococcus pneumoniae, Haemophilus influenzae and Streptococcus viridans plus Veillonella species. Data adapted from reference 34

pneumonia: experience at a community hospital. Compr Ther $1984 ; 10: 20-5$.

22. Research Committee of the British Thoracic Society and the Public Health Laboratory Service: Community-acquired pneumonia in adults in British hospitals in 1982-1983: a survey of aetiology, mortality, prognostic factors and outcome. Q J Med 1989;62:195-222.

23. Mohamed AR, Evans DA. The spectrum of pneumonia in 1983 at the Riyadh Armed Forces Hospital. J Infect 1987;14:31-7.

24. Holmberg H. Aetiology of community-acquired pneumonia in hospital treated patients. Scan I Infect Dis 1987;19:491-501.

25. Levy M, Dromer F, Brion N, Leturdu F, Carbon C. Community-acquired pneumonia. Importance of initial noninvasive bacteriologic and radiographic investigations. Chest 1988;92:43-8.

26. Lim I, Shaw DR, Stanley DP, Lumb R, McLellan G. A prospective study of the aetiology of community-acquired pneumonia. Med J Aust 1989;151:87-91.

27. Ausina V, Coll P, Sambeat M, et al. Prospective study on the etiology of community-acquired pneumonia in children and adults in Spain. Eur J Clin Microbiol Infect Dis 1988;7:342-7.

28. Ortqvist A, Kalin M, Lejdeborn L, Lundberg B. Diagnostic fiberoptic bronchoscopy and protected brush culture in patients with community-acquired pneumonia. Chest 1990;97:576-82.

29. Kauppinen MT, Herva E, Kujala P, Leinonen M, Saikku P, Syrjala $\mathrm{H}$. The etiology of community-acquired pneumonia among hospitalized patients during a Chlamydia pneumoniae epidemic in Finland. J Infect Dis 1995;172:1330-5.

30. Marrie TJ. Pneumonia. In: CJ Bulla and C Kaufmann, eds. Infections in the Elderly. London: Bailliere Tindal. [In press]

31. Berntsson E, Lagergard T, Strannegard O, Trollfors B. Etiology of community-acquired pneumonia in out-patients. Eur J Clin Microbiol $1986 ; 5: 446-7$.

32. Langille DB, Yates L, Marrie T]. Serologic investigation of pneumonia as it presents to a physician's office. Can J Infect Dis 1993; 4:328-32.

33. Erard PH, Moser F, Wenger A, et al. Prospective study on community-acquired pneumonia diagnosed and followed up by private practitioners. In: Program and Abstracts of the $31 \mathrm{st}$ Interscience Conference on Antimicrobial Agents and Chemotherapy. Chicago, September 29-October 2, 1991. Washington: American Society for Microbiology, 1991:108.

34. Marrie TJ, Peeling RW, Fine MJ, Singer DE, Coley CM, Kapoor WN. Ambulatory patients with community-acquired pneumonia: the frequency of atypical agents and clinical course. Am J Med 1996;101:508-15.

35. Marrie TJ. Epidemiology of community-acquired pneumonia in the elderly. Semin Respir Infect 1990;5:260-8.

36. Clavo-Sanchez AJ, Giron-Gonzalez JA, Lopez-Prieto D, et al. Multivariate analysis of risk factors for infection due to penicillin-resistant and multidrug-resistant Streptococcus pneumoniae: a multicenter study. Clin Infect Dis 1997;24:1052-9. 


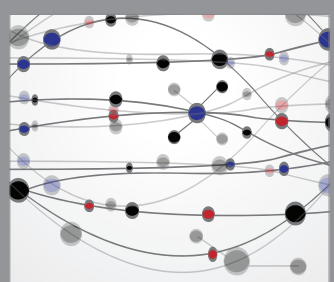

The Scientific World Journal
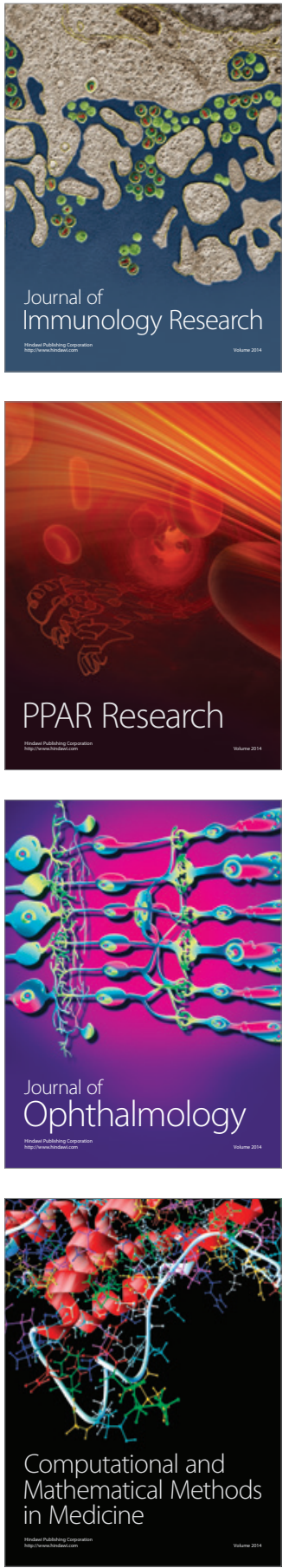

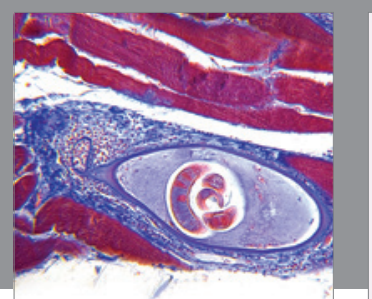

Gastroenterology Research and Practice

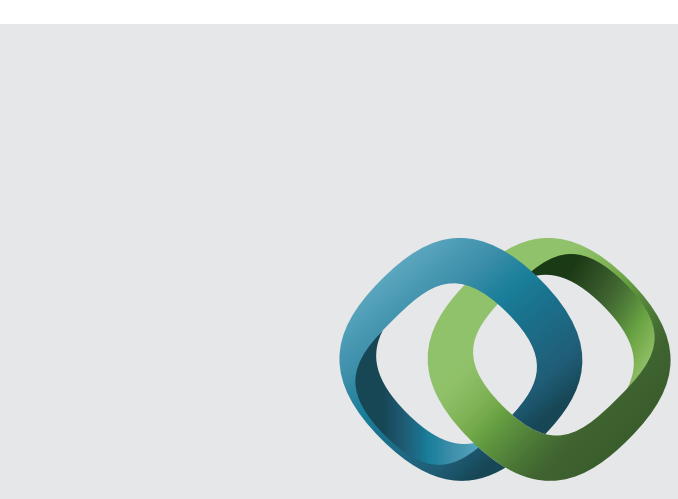

\section{Hindawi}

Submit your manuscripts at

http://www.hindawi.com
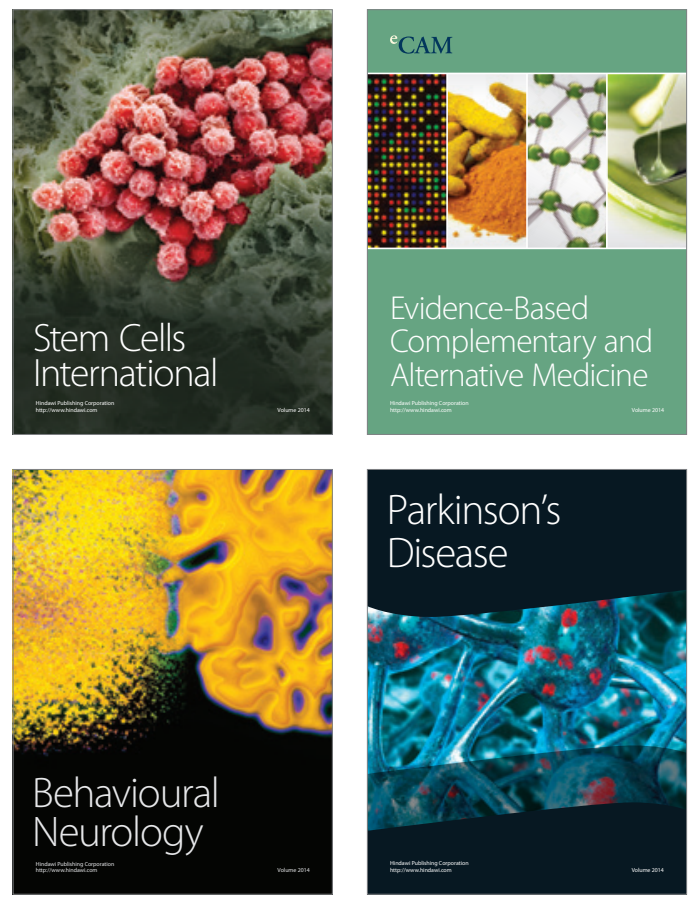
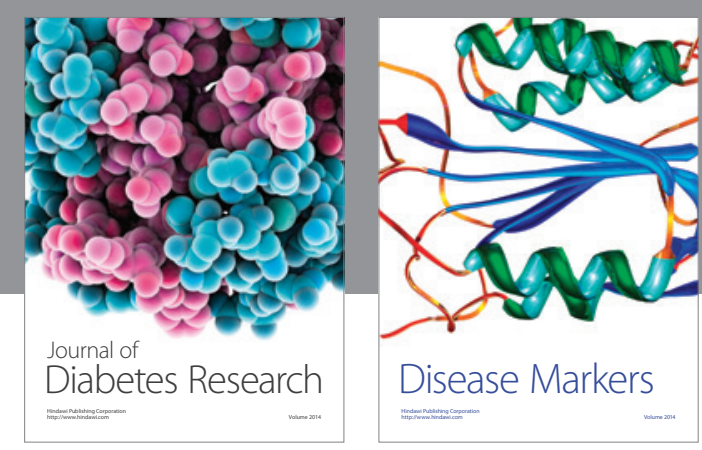

Disease Markers
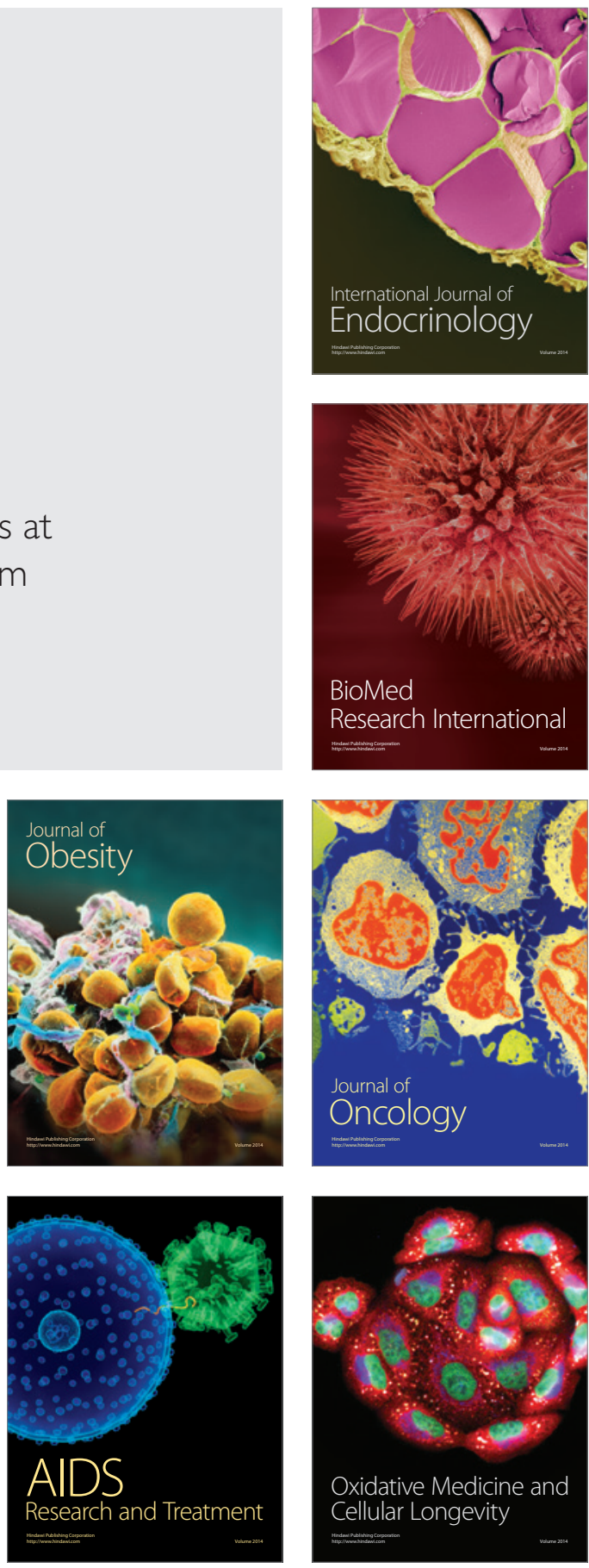